\title{
Governança Eleitoral e Ativismo Judicial: Uma Análise Comparada sobre o Impacto de Decisões Judiciais nas Regras do Processo Eleitoral Brasileiro
}

\author{
Ana Paula de Almeida Lopes ${ }^{1}$ \\ ${ }^{1}$ Professora adjunta do Centro Universitário da Faculdade de Desenvolvimento do Rio Grande do Sul \\ (FADERGS). Porto Alegre, RS. Brasil. \\ E-mail: anapaula98@yahoo.com, https:/ / orcid.org/0000-0002-4500-5011

\section{INTRODUÇÃO}

$\mathrm{N}$ o Brasil, a atuação do Poder Judiciário no âmbito da competição eleitoral tem sido objeto de debate por cientistas políticos desde a década de 1990, dando-se ênfase a duas vertentes de análise: uma de caráter institucionalista, cujo exame atém-se à institucionalização da Justiça Eleitoral como órgão de governança eleitoral (Sadek, 1995; Taylor, 2006); e outra que trata da judicialização da competição política decorrente da alteração de regras do processo eleitoral por meio das decisões emitidas pelo Judiciário (no caso, o Supremo Tribunal Federal e o Tribunal Superior Eleitoral), a exemplo da decisão sobre a verticalização das coligações partidárias para as eleições proporcionais em 2002, considerada um marco de um padrão decisório mais ativista $^{1}$ do STF quanto ao contencioso eleitoral (Fleischer e Barreto, 2009; Barroso, 2009; Marchetti, 2008).

Este trabalho de pesquisa tem por objetivo analisar as especificidades do modelo de governança eleitoral brasileiro a partir de um estudo comparado, sob a perspectiva da primeira vertente, a fim de avaliar se as regras institucionais produzem resultados diferentes no que concerne o ativismo judicial em relação ao processo eleitoral. Logo, para identificar as peculiaridades do modelo de governança eleitoral brasileiro, importa avaliar as suas principais características como um órgão judicializado com base em uma análise comparada com outros países que, da mesma forma, apresentam estruturas semelhantes de regimes presidencialistas federativos e de sistema judicial, quais sejam: Argentina, México e Estados Unidos. 
Sendo assim, o estudo se alicerçou em quatro critérios de análise: a) modelo de governança eleitoral, a partir da classificação de López-Pintor (2000); b) existência de justiça eleitoral especializada; c) modelo de controle de constitucionalidade; e d) atuação da mais alta corte de justiça como tribunal recursal e/ou constitucional e, por conseguinte, sua (possível) influência no processo eleitoral. Destaca-se que este último critério corresponde à verificação de mudança ou não de uma regra eleitoral e/ou partidária a partir de uma decisão judicial.

O artigo é dividido em quatro partes. A primeira tratará da conceituação e definição do termo "governança eleitoral" (electoral management), bem como da classificação dos modelos de governança eleitoral com base nos critérios de posição institucional em relação às outras instituições do Estado e do vínculo institucional dos membros que compõem o Organismo Eleitoral desenvolvidos na obra de Lopez-Pintor (2000) e referenciados por Marchetti (2008). No segundo item, será abordado o modelo de governança eleitoral brasileiro a partir das variáveis "modelo de governança eleitoral" e "padrão de interferência do Judiciário no processo eleitoral". Na terceira e última parte, serão aplicadas as mesmas variáveis à análise dos casos da Argentina, dos Estados Unidos e do México.

\section{GOVERNANÇA ELEITORAL}

Inicialmente, o termo "governança eleitoral" passa a ter importância para o estudo das instituições eleitorais a partir da utilização do termo "governança" como um elemento a ser considerado para a estabilização democrática. A primeira geração de análise sobre o termo "governabilidade" surgiu na década de 1960, tendo como precursor Samuel Huntington. Na obra Political Order in Changing Societies (1968), o autor analisa que o declínio da ordem política, o enfraquecimento da autoridade, bem como efetividade e legitimidade política foram resultado do excesso de participação e da sobrecarga de demandas nascidas no período pós-II Guerra Mundial.

Em análise posterior sobre a crise da democracia, o ponto central de Huntington (1975) é de que a democracia americana teria produzido um aumento substancial na atividade governamental e, ao mesmo tempo, um declínio substancial na autoridade governamental. $\mathrm{O}$ foco das preocupações práticas passou da categoria de "construção de- 
mocrática" para a de estabilidade política, ou seja, da preservação da ordem e da governabilidade.

A partir disso, o desafio da autoridade política frente ao aumento de demandas e participação popular no controle das instituições causa uma "virada teórica" que teve versões e desdobramentos diferentes em países centrais e periféricos. Nos países industrializados, o diagnóstico de Huntington da crise democrática era atribuído a uma presumível sobrecarga de demandas, enquanto que nos países periféricos a preocupação de Huntington era com a sua debilidade institucional e consequente ingovernabilidade (Fiori, 1995).

De forma paralela, surge uma segunda geração de análise sobre a governabilidade e sua crise ligada às condições de sustentação das políticas de ajuste em contexto democrático, liderada pelo Fundo Monetário Internacional (FMI) e pelo Banco Mundial. É a partir desse modelo de análise que surgem os conceitos de governança ou governance (Santos, 1997).

Para o Banco Mundial, segundo Santos (1997:8), a definição geral de governance é "o exercício da autoridade, controle, gerenciamento, poder de governo". Associada à capacidade governativa vem a noção de good governance que seria essencial para um desenvolvimento de políticas econômicas sólidas que incorporem a equidade social e os direitos humanos.

Esse pressuposto de "bom governo" é incorporado no Brasil, de modo que o termo "governança" ou governance passa a integrar a agenda de discussão brasileira sobre o Estado a partir da década de 1990, em face da imposição de um modelo de ajuste da economia dentro do marco neoliberal (Santos, 1997).

O conceito de governança passa a ser utilizado sobre outros aspectos que não apenas as funções gerenciais e administrativas do Estado. Dentre eles está a governança eleitoral (electoral management) - entendida como um conjunto de regras e instituições que definem a competição político-partidária - que passou a ganhar destaque a partir da terceira onda de democratização. Até então, as eleições multipartidárias não eram comuns na maioria dos países em desenvolvimento, de modo que a governança eleitoral também emergiu como um elemen- 
to essencial para a estabilização democrática (López-Pintor, 2000). Autores como Pastor (1999) e López-Pintor (2000) foram pioneiros na definição de alguns conceitos elementares para o estudo das instituições responsáveis pelo gerenciamento do processo eleitoral em diferentes países, os quais serão aprofundados a seguir.

Desse modo, o termo governança nasce com uma conotação de neutralidade que é transferida para a expressão "governança eleitoral" e, consequentemente, é contemporizada para a percepção da relação entre o Poder Judiciário e os aspectos gerenciais do modelo de governança eleitoral brasileiro.

A governança eleitoral opera em três diferentes níveis²: 1) formulação das regras (rulemaking); 2) aplicação de regras (rule application); 3) adjudicação das regras (rule adjudication) (Marchetti, 2008).

O primeiro nível, "formulação de regras", trata da definição das regras básicas da competição eleitoral. Ou seja, a determinação da fórmula eleitoral, os distritos eleitorais, as datas em que serão realizadas as eleições, a organização dos órgãos responsáveis pela administração das eleições etc.

Na fase de "aplicação das regras", tem-se a implementação e o gerenciamento do jogo político, isto é, o registro dos partidos, candidatos e eleitores, a distribuição das urnas, dentre outras regras que garantam a transparência e neutralidade da competição eleitoral.

No terceiro nível de "adjudicação das regras", ocorre a administração dos litígios entre os competidores. Concomitante à solução dos conflitos eleitorais, nesse nível também são determinados os procedimentos, executa-se a contagem dos votos e publicam-se os resultados da disputa eleitoral.

Esses três níveis de governança eleitoral nem sempre são realizados pelo mesmo órgão. A fase de formulação de regras eleitorais está definida pelo Código Eleitoral e pela Constituição. Já a "aplicação de regras" e a "adjudicação de regras" ficam sob a responsabilidade de um órgão específico, o qual é normalmente tratado como Electoral Management Board (EMB), ou simplesmente como Organismo Eleitoral (OE). Em suma, uma função comum a todos os OEs é a prer- 
rogativa de administrar, operacionalizar, gerenciar e tomar decisões administrativas e logísticas para a realização das eleições.

Marchetti (2008), a partir da pesquisa de López-Pintor e de um estudo elaborado pelo Institute for Democracy and Electoral Assistance (Idea), identifica dois critérios para a classificação dos OEs : a posição institucional, ou seja, a sua posição em relação às outras instituições do Estado; bem como o vínculo institucional dos seus membros, o qual diz respeito aos requisitos básicos para ser membro do OE. O primeiro critério abrange quatro modelos:

a) independente: formado por uma comissão eleitoral ou tribunal independente do Poder Executivo;

b) misto: o governo controla as eleições mediante a supervisão de um grupo formado por juízes, políticos e especialistas;

c) governamental: o governo tem o controle total do processo eleitoral;

d) duplamente independente: diferentes grupos, todos independentes do Executivo, são responsáveis pela administração, supervisão e regulamentação das eleições. (2008:871)

De acordo com o segundo critério, os membros do OE poderão ter os seguintes vínculos institucionais:

a) de carreira: quando todos os seus membros forem recrutados dentre os integrantes do Poder Executivo;

b) partidário: quando os membros do $\mathrm{OE}$ mantiverem vínculos com os partidos políticos;

c) especializado: quando os membros forem escolhidos por critérios não partidários, ou que vedem qualquer vinculação partidária;

d) combinado: quando o OE é composto tanto por membros indicados por partidos quanto por membros não partidários. (idem:872)

Além desses critérios, ressalta-se que o formato de um OE pode variar com a tradição política e cultural e também com as experiências de 
evolução democrática. Os principais fatores que condicionam o desenvolvimento dos sistemas eleitorais em diferentes partes do mundo são os seguintes: tradição do constitucionalismo; interesse das lideranças em negociar durante um período de transição; extensão da economia; e amplitude dos protestos em massa (idem, 2000).

\section{O MODELO DE GOVERNANÇA ELEITORAL DO BRASIL}

Segundo Pereira (2012), o Brasil apresenta um modelo de governança eleitoral independente, isto é, o processo eleitoral é integralmente organizado por um tribunal independente dos poderes Executivo e Legislativo. Juntamente com a Costa Rica são os únicos dois países que apresentam este modelo de governança eleitoral na América Latina, o qual, para López-Pintor (2000), é o mais comum em novas democracias.

Destaca-se que a independência do Poder Executivo e Legislativo na classificação de Lopéz-Pintor (2000) é normativa, uma vez que, no Brasil, os ministros do Supremo Tribunal Federal, os quais também integram o Tribunal Superior Eleitoral, são indicados pelo chefe do Poder Executivo com a ratificação do Senado Federal. Desse modo, as decisões dos ministros tornam-se sensíveis à política que deseja imprimir aquele que os nomearam, tornando a independência institucional dos tribunais meramente formal.

Em relação ao aspecto institucional, a estrutura do Poder Judiciário brasileiro acaba moldando a estrutura institucional do modelo de governança eleitoral, bem como a forma de solução do contencioso eleitoral.

Pela Constituição de 1988 (art. 118), são órgãos da Justiça Eleitoral o TSE, os Tribunais Regionais Eleitorais (TREs), os juízes eleitorais e as Juntas Eleitorais. No padrão institucional brasileiro de governança eleitoral, o TSE é uma instituição independente e autônoma com relação aos Poderes Executivo e Legislativo (Zauli, 2011). Essa autonomia e independência estaria relacionada à sua capacidade de atuar livre dos interesses político-partidários, desde a criação da Justiça Eleitoral em 1932 (Sadek, 1995).

Nesse sentido, para Sadek (1995) a sua estrutura principal tem se mantido a mesma desde a sua fundação até os dias atuais, o que 
corrobora para a indicação de seu êxito institucional e da inexistência de grandes controvérsias sobre sua existência e atuação. Na mesma linha, para Fleischer e Barreto (2009) a sua consolidação como órgão essencial na gestão do processo eleitoral deve-se ao fato de que a legitimidade para o exercício de tal prerrogativa nunca foi questionada pelos partidos perdedores.

Uma das peculiaridades estruturais da Justiça Eleitoral é não possuir quadro judicante próprio, uma vez que seus membros são recrutados de outros órgãos judiciários, exercendo as funções da Justiça Eleitoral em concomitância com as atividades inerentes ao órgão judiciário que integram, pelo período de dois anos, podendo ser reconduzidos por igual período.

Observa-se que não há na governança eleitoral brasileira um Organismo Eleitoral com corpo de direção próprio e exclusivo. Todas as instâncias da governança eleitoral brasileira contam com a "regra da interseção" para a composição de seus membros que acompanham a estrutura do Poder Judiciário. Dessa forma, a interseção eleitoral máxima (TSE) possui interseção com as últimas instâncias judiciais, e as instâncias inferiores possuem interseção com as instâncias judiciais superiores.

Além de ter interseção com as últimas instâncias judiciais, o TSE tem forte interseção com o STF, o que o torna, segundo Marchetti (2015), seu órgão - não de direito, mas de fato - para assuntos eleitorais. O predomínio do STF sobre o TSE se dá pelo fato de que a presidência e a vice-presidência são cargos exclusivos dos ministros do Supremo, o que eleva a governança eleitoral ao nível constitucional.

Além disso, na maior parte das vezes o STF nem mesmo conhece do recurso por entender que o TSE é a última palavra em matéria eleitoral. Tal comportamento é reforçado pela irrecorribilidade das decisões do TSE (art. 22 do Código Eleitoral), salvo aquelas que declararem a invalidade de lei ou ato contrário à Constituição Federal e as denegatórias de habeas corpus e mandado de segurança, quando autorizado recurso ordinário para o STF, o que abre uma larga via entre o TSE e o STF, sobretudo em relação aos mandados de segurança ${ }^{3}$.

Assim, a principal forma de inclusão do Supremo Tribunal Federal no modelo de governança eleitoral brasileiro se dá pelo exercício do 
controle de constitucionalidade das leis. Pela via concentrada ou difusa, o STF tem o poder de ratificar as mudanças nas regras da competição eleitoral praticadas pelo TSE, ou até mesmo provocá-las antes de uma deliberação deste tribunal. Logo, a interseção entre ambas as cortes e a função de controle de constitucionalidade tornam o Supremo um segundo Organismo Eleitoral.

Segundo Marchetti (2015), mesmo a elevação ao nível constitucional das questões eleitorais quando levadas, pela via recursal ou pela via concentrada, ao STF não significa um enfraquecimento do TSE como última palavra em matéria eleitoral. Ao contrário, a importância do TSE teria aumentado a partir da década de 1990 em razão do número de processos distribuídos que passou de centenas para milhares devido à promulgação da Lei dos Partidos Políticos (nº 9.096/95) e da Lei das Eleições (no 9.504/97).

A maioria dos processos que chega ao TSE diz respeito ao contencioso eleitoral, mas deve-se chamar atenção para outro instrumento que não está relacionado ao contencioso eleitoral, mas que tem por finalidade sanar qualquer dúvida entre os competidores políticos e os seus administradores antes do início do processo eleitoral: a Consulta. Prevista no art. 23 do Código Eleitoral ${ }^{4}$, a consulta é um instrumento administrativo de caráter instrutivo e preventivo e, portanto, a resposta dada pelo TSE é sempre feita em tese, pois o que existe é apenas uma dúvida sobre a interpretação da legislação. Poderá servir de orientação a um juiz na decisão de um caso concreto que venha a acontecer no futuro, mas não há vinculação da resposta dada em consulta com a respectiva decisão judicial (Marchetti, 2015). Contudo, através da Consulta o TSE promoveu (re)interpretações até mesmo do texto constitucional que são reproduzidas nas resoluções editadas pelo TSE. Ou seja, em razão da sua prerrogativa de produzir instruções para o processo eleitoral, o TSE acaba incorporando nestas as suas respostas às consultas, as quais são produzidas em tese. Em razão disso, algumas instruções do TSE foram contestadas no STF por meio da Ação Direta de Inconstitucionalidade (ADI), cuja admissibilidade para julgamento foi negada pela corte em alguns casos, ratificando a última decisão do TSE.

Comparado a outros ramos do Direito, o número de processos julgados pelo Supremo referente ao tema de direito e processo eleitoral não é alto. Foi de 0,22\% (194 processos de um total de 80.062) em 2016 e no ano de 2014 (ano de eleições nacionais) este número subiu para 
0,58\% (460 processos de um total de 79.991), conforme dados fornecidos pelo Portal de Informações Gerenciais do STF.

Conforme dados do mesmo portal, o número de ADIs julgadas pelo órgão é pequeno. De 1988 até dezembro de 2013, foram julgadas pelo STF um total de $88(0,25 \%)$ ADIs referentes à matéria de direito e processo eleitoral de um total de 3.526 processos. Além disso, das 88 ADIs, 16, o equivalente a $18 \%$, tiveram negado o seguimento ou não foram admitidas para julgamento.

Isso se deve ao fato de que o STF ainda mantém alguns critérios de análise para o exame de admissibilidade dos recursos e ações que chegam até ele. Para esta corte, somente os atos que violem diretamente a Constituição Federal podem ser impugnados mediante controle abstrato. A impugnação de muitas resoluções do TSE não são sequer admitidas pelo entendimento de que se trataria apenas de uma regulamentação da lei eleitoral em vigência, conforme se denota no caso da ADI $n^{\circ} 1.822 / D F$, em que o STF manifestou o entendimento de que a Resolução no 20.106/98 do TSE apenas teria reproduzido dispositivos da Lei 9.504/97, razão pela qual não deveria ser conhecido ${ }^{5}$.

Por outro lado, quando as resoluções do TSE dispusessem de conteúdo autônomo e abstrato, isto é, que inovassem a legislação eleitoral como "normas primárias", seriam passíveis de controle abstrato de constitucionalidade. Todavia, tais critérios para a admissibilidade de julgamento não são tão rígidos quanto possam parecer. Tem-se o exemplo da Resolução no 20.993/2002, que determinou a observância dos partidos políticos do princípio da verticalização, cuja impugnação via controle abstrato de constitucionalidade não foi conhecido pelo Supremo, no julgamento da ADI n⿳⺈ 2.628-3/DF, por não ter se vislumbrado ofensa direta a qualquer dispositivo constitucional.

Apesar da importância dos mecanismos constitucionais e legais para a chegada de controvérsias eleitorais às cortes judiciais, isso por si só não determina a admissibilidade de julgamento dessas questões pelas cortes. A admissibilidade pelo STF no julgamento de questões eleitorais fundamentada na sua prerrogativa de "intérprete da constituição" tem muito mais a ver com o perfil do modelo de governança do que com os mecanismos institucionais que possibilitam o acesso recursal e concentrado de questões eleitorais ao STF. Consequentemente, tal perfil abre a possibilidade de que, segundo Marchetti 
(2015), o TSE possa decidir sobre as regras do jogo eleitoral por meio da interpretação do texto constitucional.

Observa-se que o modelo de atuação do Organismo Eleitoral brasileiro, visto como essencialmente neutro pelos principais teóricos da governança eleitoral, apresenta um perfil de atuação que, por influência do histórico de atuação do STF e TSE, bem como dos mecanismos institucionais gerados pelo novo constitucionalismo, ultrapassa as regras institucionais que visam estabelecer a neutralidade do Organismo Eleitoral.

Em síntese, o modelo de governança eleitoral brasileiro é judicializado desde a sua criação e, em razão da atribuição do controle de constitucionalidade das leis ao STF e da sua interseção com o TSE, é constituído por uma dupla institucionalidade marcada pela interface de ambas as cortes. Apesar disso, é possível verificar características semelhantes como o controle de constitucionalidade das leis por uma corte suprema dentro de um regime presidencialista e federativo em outros modelos de governança eleitoral. Passaremos a um estudo comparado com os países Argentina, México e Estados Unidos, com o objetivo de encontrar, com base nas semelhanças entre os países, diferenças que possam ser utilizadas como variáveis explicativas das peculiaridades do modelo de governança eleitoral brasileiro.

\section{ANÁLISE COMPARADA: O MODELO DE GOVERNANÇA ELEITORAL E A SOLUÇÃO DO CONTENCIOSO ELEITORAL NOS CASOS DA ARGENTINA, MÉXICO E ESTADOS UNIDOS}

A partir do que foi exposto até aqui, verificamos o reconhecimento por grande parte dos pesquisadores de que o $\mathrm{OE}$ brasileiro é independente (López-Pintor, 2000; Marchetti, 2008; Pereira, 2012) e judicializado (Marchetti, 2008). Apesar disso, entende-se que a atuação mais ativista do $\mathrm{OE}$ brasileiro no que concerne à alteração de regras da competição política está mais relacionado ao perfil de atuação do Judiciário do que ao modelo de governança eleitoral adotado. Para comprovar essa particularidade do modelo brasileiro, faremos uma análise comparada a partir de semelhanças e diferenças com outros modelos de $\mathrm{OE}$ que também admitem a solução do contencioso eleitoral pelo Poder Judiciário. 
Reitera-se que serão analisados os casos da Argentina, México e Estados Unidos a partir dos seguintes critérios de análise: a) modelo de governança eleitoral; b) existência de justiça eleitoral especializada; c) modelo de controle de constitucionalidade; e d) atuação da mais alta corte de justiça como tribunal recursal e/ou constitucional e, por conseguinte, sua (possível) influência no processo eleitoral.

O Idea (International Institute for Democracy and Electoral Assistance), que se trata de uma organização intergovernamental que atua desde 1995 como centro de estudos das eleições realizadas em todo o mundo, publicou, em 2007, estudo comparativo sobre o perfil das OEs de 214 países. Em posterior divulgação de dados, no ano de 2014, os perfis de Brasil, Argentina, Estados Unidos e México permaneceram os mesmos, conforme demonstrado no quadro abaixo:

Quadro 1

Comparação entre os modelos de governança eleitoral da Argentina, Brasil, Estados Unidos e México

\begin{tabular}{lcc}
\hline País & Modelo de governança & Nome da OE \\
\hline Argentina & Misto & $\begin{array}{c}\text { Ministério do Interior e } \\
\text { Câmara Nacional Eleitoral } \\
\text { Brasil }\end{array}$ \\
Estados Unidos & Independente & Tribunal Superior Eleitoral \\
México & Governamental & Autoridades locais \\
\hline
\end{tabular}

Fonte: A partir de informações disponíveis em: www.idea.int

Para Marchetti (2008), a Argentina seria o único país na América Latina que adota o modelo misto, em que uma parte da governança é realizada por um Organismo Eleitoral vinculado ao Ministério do Interior e a outra parte é prerrogativa de um órgão independente. Pela parte governamental funciona a Direção Nacional Eleitoral (DNE), cujas funções são a administração e a execução do processo eleitoral (rule application). Pelo lado independente, funciona a Câmara Nacional Eleitoral (CNE), que trata do contencioso eleitoral (rule adjudication), de modo que seus membros são todos juízes indicados pelo Presidente da República e aprovados pelo Senado. 
Como já visto, o Brasil tem sido classificado como um modelo de governança eleitoral independente, no sentido em que concentra a governança eleitoral numa única instituição, a Justiça Eleitoral.

Em relação aos Estados Unidos, esse país apresenta uma gestão eleitoral descentralizada e vinculada ao Poder Executivo, tendo em vista que a organização do processo eleitoral é concentrada nos governos locais.

Por fim, o México, a partir da reforma eleitoral nos anos 1990, passou a adotar um modelo independente e especializado, tendo-se estabelecido uma comissão eleitoral permanente e independente, o Instituto Nacional Eleitoral (INE) ${ }^{6}$, bem como o Tribunal Eleitoral do Poder Judiciário, que julga os contenciosos eleitorais de todo o país.

\section{Argentina}

A República Argentina é um país de estrutura federal, de modo que sua organização política se constitui por um Estado central que convive com 23 estados locais denominados "províncias" e com a Cidade Autônoma de Buenos Aires. Os poderes do Estado central foram delegados pelas províncias, do que pode se assumir que tudo aquilo que não tenha sido objeto de delegação continua pertencendo a essas últimas (Thamay e Bervic, 2012).

Cada província tem autonomia para ditar a sua própria legislação eleitoral, sendo que as legislações eleitorais da província se aplicam às eleições provinciais, enquanto que as eleições nacionais são reguladas por leis nacionais e por órgãos também nacionais (Pereira, 2012).

No âmbito nacional, uma parte da governança é realizada pela Direção Nacional Eleitoral (DNE), a qual é vinculada ao Ministério do Interior (Poder Executivo). Tem por função prover a infraestrutura para as eleições, administrar o Fundo Partidário e convocar as eleições.

Quanto ao contencioso eleitoral, ele fica a cargo da Justiça Eleitoral, criada no ano de 1962 e incorporada ao Poder Judiciário no ano seguinte$^{7}$. No âmbito nacional, a Justiça Eleitoral é formada pela Câmara Nacional Eleitoral (Cámara Nacional Electoral - CNE), os Tribunais Eleitorais Provinciais (Tribunales Electorales Provinciales) e as 
Juntas Eleitorais (Juntas Electorales). A Justiça Eleitoral tem ainda as funções de controle, administração e registro eleitoral.

A Câmara Nacional Eleitoral opera como um tribunal superior eleitoral. É composta por três juízes, nomeados pelo Presidente da República, após aprovação do Senado. Atua como segunda instância do contencioso eleitoral que é decidido em primeira instância pelos juízes eleitorais. Também é responsável pelo Registro Nacional de Eleitores e pela coordenação das Juntas Nacionais Eleitorais, encarregadas da recepção e contagem dos votos em cada província e na Capital Federal.

Desse modo, o Organismo Eleitoral da Argentina enquadra-se no "modelo misto", ou seja, o governo controla as eleições por meio da Direção Nacional Eleitoral, vinculado ao Ministério do Interior (Executivo), sendo que a administração e o contencioso eleitoral cabem a um grupo formado por juízes, membros do Poder Judiciário.

\section{Interferência do Judiciário no processo eleitoral argentino}

Na Argentina, a criação da Justiça Eleitoral no ano de 1962 (Decreto $7.163 / 63$ ) e a sua incorporação ao Poder Judiciário (Decreto-lei $6.407 / 63)$, permitem considerar como princípio geral a judicialização das questões eleitorais e partidárias.

A Corte Suprema de Justiça da Nação (CSJN), assim como o Brasil, exerce ambas as funções de corte recursal e corte constitucional, de modo que possui autoridade definitiva na interpretação da Constituição Nacional da Argentina. Os juízes da Corte Suprema também são designados pelo Poder Executivo com a ratificação do Senado Federal (Thamay e Bervic, 2012).

A sua atuação como corte constitucional se dá mediante o controle de constitucionalidade difuso, ou seja, as controvérsias constitucionais levadas à Corte Suprema são oriundas de litígios individuais e não a partir da lei "em tese", de modo que o mecanismo constitucional utilizado é o "Recurso Extraordinário".

Controvérsias eleitorais podem chegar à CSJN não por impugnação da lei em tese, mas a partir de casos individuais, após decisão da Câ- 
mara Nacional Eleitoral (CNE), cujas decisões são obrigatórias para os 24 juizados federais de primeira instância com competência eleitoral e para as respectivas 24 Juntas Nacionais Eleitorais ${ }^{8}$.

Entretanto, a partir da análise de alguns casos concretos, observa-se uma forte tendência das decisões da CNE, equivalente em hierarquia ao Tribunal Superior Eleitoral no Brasil, de que as questões de ordem contenciosa-eleitoral não devem ser decididas pelo tribunal.

A título de exemplo, um dos primeiros casos decididos pela Câmara Nacional Eleitoral, após a incorporação da Justiça Eleitoral ao Judiciário, é o caso "Federação Nacional de Partidos de Centro", julgado em 16/7/1963, o qual se tratava de um recurso de queixa, interposto pela Federação Nacional dos Partidos de Centro na província de Entre Ríos, contra as instruções ditadas em matéria de cômputo de votos em branco. Naquele momento, foi decidido pelo CNE que as questões de ordem contenciosa-eleitoral não incumbem à sua jurisdição extraordinária. A partir disso, a Junta Eleitoral Nacional de Entre Ríos passou a se remeter à referida sentença do $\mathrm{CNE}$, afirmando que as decisões e trâmites contencioso-eleitorais são alheias à competência judicial específica dos tribunais da Nação (Campos, 1964).

Passa a ter início a formação de um critério de julgamento do CNE no sentido de que os organismos eleitorais não são especificamente juízes ou tribunais enquanto atuam mediante consultas ou instruções. Há opinião coincidente em negar caráter judicial às juntas eleitorais que, apesar de integradas com magistrados do Poder Judiciário e com a prerrogativa de realizar atos jurisdicionais, são órgãos meramente administrativos encarregados da administração comicial, do escrutínio, de entender nas causas a validez ou a nulidade da eleição e de proclamar os eleitos.

Igualmente, no caso "Cafiero y Mejide", tendo em vista que se fundamenta no projeto de lei federal dos deputados Juan P. Cafiero e Graciela Férnandez Mejide que visava garantir um terço dos cargos partidários e eleitorais para as mulheres, o Tribunal Eleitoral e a Corte Suprema não admitiram o recurso para exame. Tratava-se de lei aprovada na província de Santa Fé, Lei 10.802/92, que estabelecia uma cota de participação para as mulheres (cupo feminino), de forma intercalada ou sucessiva, na lista de candidatos apresentada pelos partidos políticos. A vigência desta lei juntamente com a "Ley de 
Lemas" ${ }^{\prime \prime}$ trouxe alguns problemas para a sua implementação nessa província, de modo que não foi respeitada a cota de participação das mulheres nas internas partidárias.

Três mulheres candidatas ingressaram com recurso perante o Tribunal Eleitoral da província, alegando que não havia sido respeitada a porcentagem feminina. $\mathrm{O}$ recurso foi rechaçado pelo Tribunal, o que levou as candidatas a interporem recurso de inconstitucionalidade por arbitrariedade para a Corte Suprema de Justiça que novamente denegou o recurso com a seguinte fundamentação:

La pretensión de que, por via de uma apelación a los princípios, esta Corte corrija los claros e inequívocos términos de la ley, no puede ser acogida favorablemente, toda vez que lo contrario daria lugar a um desborde de competencia jurisdiccional, frente a ámbito de atribuciones privativo del legislador ordinario. (Blando, 2002:149)

Em resumo, neste caso o Tribunal Eleitoral Provincial declarou-se incompetente e carente de atribuições, em razão de que foi interposto recurso de inconstitucionalidade. Blando (2002) considera este argumento impróprio, uma vez que é competência do Tribunal Eleitoral oficializar a lista ou as listas que contradigam o art. $2^{\circ}$ da Lei $\mathrm{n}^{\circ}$ 10.802/92.

Na Argentina, assim como no Brasil, o contencioso eleitoral cabe ao Judiciário, formado pela Câmara Nacional Eleitoral (CNE), os Tribunais Eleitorais Provinciais e as Juntas Eleitorais. As controvérsias constitucionais relacionadas ao processo eleitoral são levadas à Corte Suprema da Nação por meio do controle de constitucionalidade difuso, que, porém, nos casos apresentados foram remetidos ao Poder Legislativo, pois o entendimento majoritário da Corte Suprema é de que se trata de questões não judicializáveis e, portanto, não devem ser examinadas pelo Judiciário.

\section{Estados Unidos}

Nos Estados Unidos, a administração eleitoral é altamente complexa e descentralizada, podendo-se dizer também recente. A Constituição de 1787 inovou com a criação de um Colégio Eleitoral (Electoral College), porém diz pouco sobre a administração eleitoral, a não ser por 
delegar aos estados-membros a responsabilidade de determinar os procedimentos para a escolha dos eleitores que irão compor o colégio eleitoral (López-Pintor, 2000; Pastor, 2006).

Ao longo do tempo, os estados-membros delegaram aos municípios a responsabilidade da administração eleitoral, de modo que estes têm como atribuições principais o registro dos votos, a criação da cédula eleitoral e o treinamento aos funcionários eleitorais. Pastor (2006) destaca que poucos estados dispõem de orçamento para auxiliar as autoridades eleitorais locais e, portanto, têm pouco ou nenhum poder sobre a condução do processo eleitoral. Além disso, os pontos fortes e fracos da administração eleitoral americana derivam da sua natureza descentralizada, que permite, de forma concomitante, um alto nível de autonomia e um baixo nível de uniformidade.

A única eleição executada pelo Colégio Eleitoral é aquela em que os eleitores, designados pelos candidatos e escolhidos pelos eleitores de cada estado, escolhem o presidente. Apesar destas eleições serem realizadas em âmbito federal para os cargos de presidente, vice-presidente, senador e deputado federal, elas são responsabilidade dos estados federados.

Algumas reformas de financiamento de campanha foram implementadas no início do século XX, considerando que as eleições eram altamente influenciadas pelo dinheiro. A primeira reforma profunda veio na forma da Lei de Financiamento de Campanha de 1974, depois do escândalo Watergate.

Após esse episódio, os Estados Unidos estabeleceram, no ano seguinte, uma agência reguladora eleitoral independente, a Comissão Federal Eleitoral (Federal Election Commission - FEC), com o objetivo de divulgar informações de financiamento de campanha, fiscalizar o cumprimento das disposições da lei no que diz respeito aos limites e proibições de contribuições, bem como supervisionar o financiamento público das eleições presidenciais ${ }^{10}$.

Após as eleições presidenciais de 2000, em que uma disputa pela recontagem dos votos no estado da Flórida foi decidida pela Suprema Corte, o Congresso aprovou a primeira lei federal sobre administração eleitoral chamada de "Help America Vote Act" (HAVA) em 2002. 
Esta lei estabelece padrões e requisitos nacionais para o processo de votação, mas os condiciona majoritariamente à decisão dos estados em aceitar fundos da Comissão de Assistência Eleitoral (Election Assistance Commission - EAC), criada pela mesma lei. A EAC é composta por quatros membros, dois nomeados pelos congressistas republicanos e dois pelos democratas. Não se trata de um órgão de gerenciamento eleitoral, mas primariamente um mecanismo para a transferência de fundos federais para os governos estatais a fim de que estes possam investir em novos equipamentos de votação e ampliação das listas de registro de eleitores. Destaca-se que, até a aprovação desta lei, o governo federal não gastava com as eleições e os estados gastavam muito pouco, praticamente todos os fundos estavam concentrados no nível local (Pastor, 2006). Por outro lado, Nussbaumer (2013) considera que, ao tentar uniformizar o processo eleitoral no país, esta lei poderá causar mudanças no próprio modelo de federalismo norte-americano (Nussbaumer, 2013).

As estruturas institucionais responsáveis pela administração do processo eleitoral permanecem em âmbito local, embora devam responder ao Congresso, Poder Executivo e às cortes judiciais. Na maioria dos estados, o responsável pela condução das eleições é o secretário de Estado, o qual geralmente é eleito e tende a ser um indivíduo que aspira por um cargo político mais elevado.

A EAC tem poderes muito limitados, já que qualquer ação sua requer a aprovação de três membros. Além disso, não tem poderes regulatórios, não podendo promulgar um regulamento ou realizar qualquer ação que imponha novas condições a um estado ou localidade.

Afinal, o modelo de governança eleitoral norte-americano não é independente, considerando que o FEC é um órgão independente no que concerne o gerenciamento do fundo partidário, mas não do processo eleitoral. Logo, caracteriza-se principalmente pela sua sujeição ao controle do Poder Executivo num sistema altamente descentralizado, uma vez que as eleições são gerenciadas pelos governos locais. Com a criação da EAC, em 2002, há uma tentativa de uniformização do processo eleitoral que, no entanto, não alterou o modelo de dependência do gerenciamento do processo de votação do Poder Executivo (López-Pintor, 2000; Wall, 2006). 


\section{Interferência do Judiciário no processo eleitoral americano}

Em relação ao contencioso eleitoral, ele cabe aos tribunais ordinários federais, não havendo uma justiça eleitoral especializada. Em razão do modelo difuso de controle de constitucionalidade, disputas políticas foram levadas à Corte Suprema tanto pela via recursal quanto de forma originária, dentre as quais algumas tiveram o potencial de alterar regras eleitorais, bem como o próprio resultado das votações, conforme os casos selecionados para análise neste artigo.

Importante ressaltar que no sistema difuso de controle de constitucionalidade americano vale de fato o princípio do stare decisis, por força do qual o julgamento da inconstitucionalidade de uma lei assume uma eficácia para todos (erga omnes) e, portanto, não se limita à mera não aplicação de uma lei declarada inconstitucional ao caso concreto. Quando uma lei deixa de ser aplicada pela Suprema Corte por inconstitucionalidade, passa a ser considerada uma lei morta (Cappelletti, 1984).

A Suprema Corte dos Estados Unidos tem jurisdição originária e exclusiva. Sua jurisdição abrange as decisões das cortes federais e das mais altas cortes estaduais quando estas tenham decidido alguma questão federal. Embora descentralizado quanto ao gerenciamento do processo eleitoral, na solução do contencioso eleitoral, o modelo norte-americano tende a ser mais uniforme.

Dentre os casos de maior impacto no jogo político, decididos pela Suprema Corte, estão: Buckley v. Valeo (1976), no qual se reconheceu a constitucionalidade dos limites impostos a doações diretas estabelecidos pelo Federal Election Campain Act (FECA); Gore v. Bush (2000), em que se decidiu a disputa presidencial; e Citizens United v. Federal Election Commission (2010), sendo proibida a restrição de gastos políticos independentes por empresas, associações e sindicatos com as campanhas eleitorais.

No primeiro caso, Buckley v. Valeo, em 1976, foram aprovadas medidas de reforma do financiamento de campanha, pelo Congresso americano, como um conjunto de emendas à Lei de Campanha Eleitoral Federal que impuseram limitações, dentre outras, sobre contribuições individuais e de comitês para um candidato a cargo federal, gastos dos candidatos com o seu próprio dinheiro e despesas independentes com a campanha eleitoral (Jones, 2015). 
Logo depois que essas emendas foram aprovadas, uma coalizão heterogênea, incluindo o senador James Buckley, de Nova York, ingressou com uma ação em tribunal federal alegando que as novas disposições eram inconstitucionais sob o argumento que a limitação ao uso do dinheiro para fins políticos constituiria uma violação da Primeira Emenda (liberdade de expressão), uma vez que todas as comunicações políticas significativas ensejam o gasto de dinheiro.

Levada a questão à Suprema Corte, confirmou-se a constitucionalidade dos limites das doações individuais e de comitês aos candidatos. No entanto, declarou-se que os limites obrigatórios dos gastos dos candidatos com seu próprio dinheiro, os limites de gastos independentes e os limites ao total dos gastos de campanha constituem violações da Primeira Emenda. Sendo assim, sua relevância se dá, principalmente, por ter introduzido a noção de que gastar dinheiro em nome de um candidato ou partido político é uma forma de discurso protegido e por ter estabelecido parâmetros de regulamentação de campanhas eleitorais nos Estados Unidos por mais de quatro décadas.

O segundo caso de maior relevância, Gore v. Bush, trata-se da eleição presidencial do ano 2000 que resultou na vitória do candidato republicano George W. Bush perante seu opositor, o candidato democrata Al Gore. Embora ele tivesse recebido uma quantidade superior de votos populares, Bush recebeu a maioria dos colégios eleitorais (Pastor, 2006).

Em razão da autonomia dos estados-membros de criarem, até então, suas próprias regras sobre a administração eleitoral, incluindo a de contagem e recontagem de votos, o estado da Flórida adota o sistema winner-take-all, em que o candidato mais votado obtém a totalidade dos votos daquele colégio eleitoral, que totaliza 25 votos.

Ocorreu que pela margem de diferença entre os dois candidatos (1.784 votos, equivalente a $0,5 \%$ ), a legislação da Flórida impõe a recontagem automática de votos, o que reduziu a diferença para 327 votos. Diante disso, Gore pediu a recontagem manual dos votos em quatro distritos considerados predominantemente democratas, Volusia, Palm Beach, Broward e Miami-Dade, os quais deveriam entregar os resultados até sete dias após as eleições (14/11/2000). Apenas o distrito de Volusia conseguiu cumprir a determinação legal e a justificativa pelo atraso dos demais não foi aceita pela Secretária de Estado da Flórida, Katherine Harris (Gillman, 2001). 
A seguir, a Suprema Corte da Flórida determinou a extensão do prazo para $26 / 11$ e, posteriormente, a recontagem dos votos sob o argumento de que os possíveis votos válidos dentre os 9.000 votos que não foram computados pelas máquinas poderiam alterar os resultados da eleição naquele estado. Todavia, a decisão foi suspensa pela Suprema Corte que decidiu, por maioria de cinco ministros contra quatro, que aquele processo de recontagem de votos era inconstitucional, pois não poderiam ser utilizados métodos alternativos para a recontagem dos votos no estado da Flórida. Logo, esta recontagem não poderia ser concluída de forma satisfatória dentro do prazo estipulado. Todas as recontagens deviam cessar e seria mantida a certificação de George Bush como o candidato vencedor dos 25 votos do Colégio Eleitoral daquele estado.

A decisão da Suprema Corte foi considerada per curium, ou seja, limitada às circunstâncias atuais e não poderia ser utilizada como precedente. Porém motivou a aprovação da primeira lei federal sobre administração eleitoral, chamada de "Help America Vote Act" (HAVA), em 2002, já citada anteriormente.

Outro caso de impacto no processo eleitoral, julgado pela Suprema Corte no ano de 2010, é o Citizens United v. Federal Election Commission. Primeiramente, Citizens United é uma organização conservadora que descreve sua missão como sendo dedicada a restaurar o governo dos Estados Unidos para controle dos cidadãos e procura afirmar os valores americanos de governo limitado, livre iniciativa, famílias fortes, soberania e segurança nacional. Para tanto, realiza diversos projetos de marketing, incluindo publicidade televisiva e documentários de longa-metragem (Pastor, 2006).

Em 2008, publicou um documentário intitulado "Hillary: The Movie", sobre a vida da então senadora e candidata presidencial Hillary Clinton, o qual seria exibido na TV a cabo antes das eleições primárias do Partido Democrata. Entretanto, a transmissão do documentário foi impedida por um tribunal federal de Washington DC, com base na Lei de Reforma da Campanha Bipartidária de 2002 (Bipartisan Campaign Reform Act of 2002 - BCRA), conhecida como lei "McCain-Feingold" (Liptak, 2010). Essa lei alterou a Lei de Campanha Eleitoral de 1971 que regulamentava o financiamento de campanhas políticas. Dentre as suas principais alterações estão a imposição de limites sobre as contribuições de grupos de interesse e de partidos políticos nacionais que não fossem reguladas pela FEC (soft money), e a proibição de 
qualquer anúncio pago por empresas, organizações sem fins lucrativos e também entidades sem personalidade jurídica, que utilizassem fundos da tesouraria geral da empresa ou do sindicato, dentro de 30 dias antes das eleições primárias e 60 dias das eleições gerais.

Diante da proibição da exibição do referido documentário, a Citizens United recorreu à Suprema Corte ${ }^{11}$ que em 21/1/2010 derrubou a restrição imposta pela lei "McCain-Feingold" de empresas, associações e sindicatos pagarem por anúncios políticos feitos de forma independente das campanhas eleitorais e seus respectivos candidatos. Declarou ser inconstitucional o banimento da liberdade de expressão através da limitação de comunicações independentes feitas por esses grupos, os quais devem ter garantida a liberdade de gastarem os seus recursos para apoiar ou opor um candidato por meio de propaganda e televisão. Um dos votos dissidentes foi do juiz Stevens que argumentou que a decisão da Corte ameaçava minar a integridade das instituições eleitorais do país.

Na primeira eleição presidencial após a decisão da Suprema Corte, em 2012, segundo reportagem da revista The Economist, publicada em $24 / 11 / 2012$, as doações de corporações e sindicatos superaram a cifra de 1 bilhão de dólares na disputa presidencial, sendo que o total de gastos provavelmente ultrapassou o valor de 6 bilhões de dólares. Refere ainda que existe a preocupação de alguns republicanos de que a quantidade de dinheiro externo possa reduzir a influência dos partidos políticos nas campanhas eleitorais (The Economist, 2012).

Alguns congressistas liberais apresentaram projetos para emendar a Constituição Americana e, dessa forma, derrubar a decisão da Suprema Corte no caso Citizen United v. FEC. No entanto, tal alteração é muito improvável, já que a aprovação de uma emenda constitucional nos Estados Unidos requer a aprovação de dois terços dos congressistas nas duas casas legislativas e também a aprovação de três quartos dos estados-membros.

\section{México}

A partir da década de 1970, iniciou-se no México um longo período de transição da hegemonia do Partido Revolucionário Institucional (PRI), que durou mais de setenta anos, para um sistema plural de três partidos importantes (PRI, Partido da Ação Nacional - PAN, Partido da Revolução Democrática - PRD) e várias outras siglas menores (Lemaistre, 2011). 
Já nos anos 1990, as alterações realizadas no modelo de governança eleitoral mexicano o transformaram em independente e especializado, ou seja, passa a ter um organismo eleitoral independente de qualquer vinculação com os poderes Executivo e Legislativo e seus membros são escolhidos por critérios não partidários.

O presidencialismo mexicano apresentava uma peculiaridade que era a sua hegemonia sustentada pela forte centralização do poder governamental. Além da obstrução da criação de novos agrupamentos políticos, o registro dos partidos políticos e a legalidade conferida à sua documentação ficavam a cargo da "Secretaría de Gobernación", fazendo com que a presença de novas agremiações na arena política fosse meramente testemunhal.

Somente a partir da década de 1970 que se iniciou um lento processo de democratização, especialmente com as reformas políticas e eleitorais iniciadas em 1977. Tais reformas possibilitaram o registro de partidos políticos de oposição e a introdução do sistema de representação proporcional. Se, em 1976, só um candidato concorrera à presidência; em 1982, havia sete (Ribeiral, 2012).

Com a dissidência priista em 1987, importantes setores do partido hegemônico constituíram-se como oposição à revolução institucionalizada através da formação do PRD. As eleições de 1988 foram marcadas por uma abertura política ampliada com a participação do PAN e de outras agremiações.

Além disso, o Código Federal Eleitoral (Cofipe), de 1987, formalizou a corresponsabilização partidária, que só poderia ser praticada com a efetiva institucionalização e independência da justiça eleitoral, tema que seria debatido na década seguinte. Paulatinamente, ocorreu o processo de transição política e o fortalecimento dos órgãos de administração e arbitragem eleitoral.

Como passo inicial para o fortalecimento institucional, foi criada a Lei Federal das Organizações Eleitorais (Loppe), que estabeleceu a possibilidade do Poder Judiciário, em especial da Suprema Corte da Nação, de resolver as controvérsias eleitorais. A fim de complementar a atuação do Judiciário, foi criado o "Tribunal de lo Contencioso 
Electoral" (Tricoel) responsável pelo julgamento dos conflitos políticos e por sua judicialização.

Apesar disso, o Tricoel deveria ser administrado pelo Poder Executivo e detinha um caráter dependente e transitório, de modo que essas leis iniciais não foram capazes de responder à desconfiança em relação aos resultados políticos.

As eleições de 1988 foram marcadas pela dualidade entre o controle hegemônico dos resultados das eleições e um ambiente em que novas forças disputavam o poder. A falta de idoneidade do processo eleitoral e a crise econômica resultaram em protestos por todo o país que ajudaram a impulsionar as mudanças do sistema político e de partidos.

O último passo da transição mexicana foi a regulamentação da juridicidade eleitoral. A justiça eleitoral mexicana organizou-se por meio de duas instituições principais: o Instituto Federal Eleitoral e o Tribunal do Contencioso Eleitoral (Ribeiral, 2012).

O “Instituto Federal Electoral” (IFE), criado em 1989, é responsável por administrar o processo eleitoral federal. Desde a sua formação, o IFE foi concebido como um órgão constitucional, com funcionários públicos de carreira e com recursos orçamentários independentes. As suas principais atribuições são a elaboração do registro e da jornada eleitoral, a capacitação e educação cívica, a contagem e computação dos votos e o anúncio dos resultados.

Apesar de ser tratado como um organismo jurídico autônomo, responsável por administrar a organização das eleições federais, a primeira composição do IFE ainda mantinha uma ligação com o governo, pois previa ao Secretário de Gobernación a ocupação da presidência do instituto e presença dos partidos políticos na direção do instituto.

Gómez (2011) observa que o nível de confiança na atuação do IFE tem aumentado gradativamente. No período de 2003 a 2007, houve uma diminuição do nível de desconfiança no instituto de $63 \%$ para $26 \%$, respectivamente. A autora destaca que o aumento da confiança nas instituições eleitorais ocorre num contexto de baixo nível de confiança interpessoal, em torno de $57,3 \%$, conforme pesquisa realizada em 2008. Logo, o aumento do grau de confiança no IFE pode ser visto como positivo para a estabilidade democrática no país. 
Em 1993, é extinto o "Tribunal del Contencioso Electoral" (Tricoel) e cria-se no seu lugar o "Tribunal Federal Electoral" (Trife). Uma das principais alterações na sua atuação é o fim da sazonalidade eleitoral, passando o tribunal a ter caráter permanente e nacional. Entretanto, a jurisdição do tribunal permanecia sujeita aos colégios eleitorais federais e estaduais ainda ligados ao Poder Legislativo.

Em 1994, cria-se a "Fiscalia Especializada para la Atención de Delitos Electorales" (Fepade) para o fim de realizar averiguações prévias em matéria penal e eleitoral. Mas a exigência de documentos comprobatórios de coação ou manipulação de votos para a investigação das denúncias, que deveriam ser efetuadas diretamente pelos cidadãos, dificultava o procedimento do inquérito. Faltava ainda a autonomia necessária para a institucionalização dos tribunais eleitorais no país.

A fim de viabilizar as mudanças, ao final da década de 1990, o governo mexicano estimulou a aproximação entre os partidos políticos, de modo que a reforma de 1996 representou o ponto culminante para o fim da transição política. Uma medida consensual entre as principais legendas PRI, PAN e PRD garantiu autonomia política e institucional ao então Instituto Federal Eleitoral (IFE) e ao Tribunal Eleitoral, de maneira que o Presidente da República foi desencarregado definitivamente do funcionamento dos órgãos internos do IFE e os partidos políticos perderam o direito ao voto no "Conselho Federal Electoral" (CFE) (Ribeiral, 2012).

O IFE foi fortalecido com a criação, em 1996, do "Tribunal Electoral del Poder Judicial de la Federación" (TEPJF). Dentre as suas atribuições está a possibilidade de intervir na impugnação de todo o resultado eleitoral, bem como no exercício e limitação dos mandatos eletivos. Tratava-se da primeira vez em que o Poder Judiciário atuaria de forma autônoma e independente na solução dos litígios eleitorais, os quais anteriormente, por serem tratados como "questões políticas", não deveriam estar sujeitos ao crivo do Judiciário.

Porém, destaca-se sobretudo a sua prerrogativa de criar a jurisprudência específica para todo o país. Ribeiral (2012) ressalta que em razão da força do federalismo político no México, apenas os tribunais que fazem parte do Poder Judicial podem criar critérios jurídicos obrigatórios para a aplicação de todas as regras jurídicas eleitorais. 
Em resumo, o Organismo Eleitoral do México, até as eleições de 1988, era um instrumento do governo hegemônico do PRI, o que contribuiu para o aumento da desconfiança da população no processo eleitoral. As reformas aprovadas após esse evento transformaram o OE mexicano em um órgão mais autônomo, especialmente pela criação do IFE (atual INE), que aumentou a credibilidade do processo eleitoral a ponto de que a maioria dos mexicanos considerasse as eleições de 1997 como honestas. A criação do Tribunal Eleitoral Federal, responsável pelo contencioso eleitoral de forma autônoma e independente, também tem contribuído para a estabilidade eleitoral no México (Pastor, 1999).

\section{Interferência do Judiciário no processo eleitoral mexicano}

Apesar de ter a atribuição de resolver todas as impugnações das eleições federais e proteger os direitos políticos, o "Tribunal Electoral del Poder Judicial de la Federación" não tem a prerrogativa de julgar ações de inconstitucionalidade contra leis eleitorais federais ou locais que tenham tais objetivos (Ribeiral, 2012).

O controle de constitucionalidade mexicano é atribuição da "Suprema Corte de Justicia de la Nación", que assim como os outros três países ora analisados, tem a função de "guardiã da Constituição". Todavia, o sistema de controle de constitucionalidade mexicano é concentrado, de modo que a Suprema Corte pode realizar esse controle somente por meio do mecanismo constitucional de "Acción de Inconstitucionalidad" (Rodríguez, 2012; Sánchez Gil, 2004).

O TEPJF, sendo o órgão especializado e máxima autoridade jurisdicional em matéria eleitoral, tem demonstrado comportamento mais ativista no julgamento das questões de matéria eleitoral, sendo a atuação da Suprema Corte mais limitada no caso mexicano.

Nas eleições realizadas para governador, no ano 2000, no estado de Tabasco, o PAN e o PRD impugnaram as eleições, acusando o governo estatal de intervir no processo eleitoral em favor do candidato do PRI, mediante a utilização de recursos públicos e da promoção de funcionários da "Secretaría de Comunicaciones y Transportes". O TEPJF anulou as eleições em razão de uma nulidade que não estava prevista de forma expressa na legislação eleitoral, baseando-se para tanto no princípio de igualdade de oportunidades como um elemento essencial para a existência de uma eleição democrática (Zamora, 2014). 
Outro marco ocorreu nas eleições de 2006, quando pela primeira vez na história do país, o TEPJF deliberou pela contagem de $12 \%$ das urnas após contestação formal do PRD sob a alegação de que a "Aliança para o Bem de Todos" (coligação de Obrador) não havia solicitado formalmente a abertura de todas as urnas. A polêmica jurídica fortaleceu o novo tribunal federal, criado para ser a última instância de recursos e apelações (Ribeiral, 2012).

O momento pós-eleitoral de 2006 criou intensos debates acerca da regulamentação realizada TEPFJ, especialmente no que diz respeito às urnas, às candidaturas e eleições e ao funcionamento dos partidos políticos. Foi aprovada uma reforma constitucional em matéria eleitoral, publicada no Diário Oficial em 13 de novembro de 2007, que inseriu no art. 99 da Constituição um catálogo de nulidades taxativas que deveriam ser a motivação expressa do Tribunal Eleitoral para anular uma eleição.

Porém, após a reforma constitucional, nos casos de Yurécuaro ${ }^{12}$ e Acapulco $^{13}$, a Sala Superior do Tribunal Eleitoral manteve o entendimento de anular eleições com base em princípios constitucionais e não a partir do que estivesse previsto expressamente na lei. $\mathrm{O}$ primeiro caso diz respeito às eleições municipais realizadas no município de Yurécuaro, estado de Michoacán, em novembro de 2007, em que a vitória do candidato do PRI foi impugnada pelo PAN e pela coalizão "Por um Michoacán Mejor" perante o Tribunal do Estado do Michoacán, que determinou a nulidade das eleições municipais. Os atos praticados pelo candidato do PRI que ocasionaram a impugnação incluíram o de apresentar-se na missa, no primeiro dia de campanha eleitoral, portando propaganda eleitoral; além de portar um rosário durante o encerramento da campanha, dentre outras ações que também tiveram conotação religiosa. A decisão do juiz eleitoral baseou-se em artigo do Código Eleitoral que proíbe a utilização de símbolos religiosos ou expressões na propaganda eleitoral (Grajales, 2011).

Inconformado com a decisão, o PRI interpôs um recurso de revisão constitucional eleitoral (juício de revisión constitucional electoral) perante o TEPFJ, alegando que o motivo que causou a anulação das eleições não estava previsto de forma expressa na legislação local. No entanto, o TEPFJ confirmou a decisão do Tribunal michoacano, mantendo a anulação das eleições de Yurécuaro. 
Em relação ao caso de Acapulco, município do estado Guerrero, ocorreu que nas eleições municipais de 2008 houve a vitória da Coligação "Juntos para Mejorar", a qual foi impugnada pelos Partidos Nueva Alianza (PNA), Alternativa Socialdemócrata (PAS) e Partido de la Revolución Democrática (PRD). Ao resolver o caso, o TEPJF considerou que uma eleição pode ser anulada se violar os princípios constitucionais que estabeleçam características fundamentais do processo eleitoral.

Desse modo, pode-se observar certo ativismo judicial da Justiça Eleitoral mexicana nos casos narrados, em que pese não ter sido verificada uma atuação mais protagonista da Suprema Corte de Justicia da Nação, o que pode ser explicado pelo modelo de controle de constitucionalidade concentrado adotado pelo México. Mesmo após a reforma constitucional que estabeleceu um rol de nulidades taxativas para a anulação de pleito eleitoral, o TEPJF manteve os mesmos critérios para declarar a anulação de eleições que tenham violado princípios eleitorais.

\section{CONCLUSÃO}

No presente trabalho, a comparação entre os quatro países - Brasil, Argentina, Estados Unidos e México - teve como objetivo demonstrar que apesar da presença de regras institucionais semelhantes (sistema federativo presidencialista, contencioso eleitoral decidido pelo Poder Judiciário e sistema de controle de constitucionalidade das leis), estas não são suficientes para determinar o comportamento das instituições. Cada um dos países analisados acabou desenvolvendo um padrão de comportamento próprio no que se refere ao protagonismo judicial na competição eleitoral, o que tornou necessária a análise de casos específicos a fim de avaliar a extensão do impacto das decisões judiciais na arena eleitoral em cada um deles, respectivamente.

Segue abaixo quadro que resume a comparação entre os quatro países analisados quanto ao modelo de governança eleitoral, controle de constitucionalidade, existência de justiça eleitoral especializada e a atuação da mais alta corte como tribunal recursal: 
Quadro 2

Comparação entre o modelo de governança eleitoral e a atuação do Judiciário no Brasil, Argentina, Estados Unidos e México.

\begin{tabular}{|c|c|c|c|c|}
\hline País & $\begin{array}{l}\text { Governança } \\
\text { eleitoral }\end{array}$ & $\begin{array}{l}\text { Controle de cons- } \\
\text { titucionalidade }\end{array}$ & $\begin{array}{l}\text { Poder Judiciário } \\
\text { eleitoral especia- } \\
\text { lizado }\end{array}$ & $\begin{array}{l}\text { Atuação da mais } \\
\text { alta corte como } \\
\text { tribunal recursal }\end{array}$ \\
\hline Brasil & $\begin{array}{c}\text { Independente e } \\
\text { judicializado }\end{array}$ & $\begin{array}{l}\text { Misto (difuso e } \\
\text { concentrado) }\end{array}$ & $\begin{array}{c}\text { SIM (Justiça } \\
\text { Eleitoral - TSE) }\end{array}$ & SIM \\
\hline Argentina & Misto & Difuso & $\begin{array}{c}\text { SIM - (Diretório } \\
\text { Nacional Eleitoral } \\
\text { - DNE) }\end{array}$ & SIM \\
\hline México & $\begin{array}{l}\text { Independente e } \\
\text { especializado }\end{array}$ & Concentrado & $\begin{array}{l}\text { SIM (Tribunal } \\
\text { Eleitoral do Poder } \\
\text { Judiciário da } \\
\text { Federação) }\end{array}$ & SIM \\
\hline $\begin{array}{l}\text { Estados } \\
\text { Unidos }\end{array}$ & $\begin{array}{c}\text { Vinculada ao } \\
\text { poder Executivo e } \\
\text { descentralizada }\end{array}$ & Difuso & NÃO & SIM \\
\hline
\end{tabular}

Fonte: a partir de informações disponíveis em Marchetti (2008), Constituição Federal de 1988, Lei Federal das Organizações Eleitorais do México, Decretos n 7.163/62 e 6.407/63 da Argentina e Constituição dos Estados Unidos,

Pode-se observar que todos os modelos de governança eleitoral analisados apresentam o instrumento de controle de constitucionalidade, o que tem sido utilizado pelas cortes constitucionais como uma ferramenta para uma atuação mais interventiva. Além disso, o único caso que não apresenta um Poder Judiciário Eleitoral especializado é o dos Estados Unidos, mas apesar disso apresentou casos judiciais em que ocorreram atuações mais interventoras do Judiciário na competição política, especialmente no que diz respeito ao financiamento de campanhas políticas.

Da mesma forma, o México é um caso de governança eleitoral independente que, ao contrário do Brasil, não é judicializado, mas também apresenta casos de interferência nas regras da competição política, como foi o caso de anulação das eleições por violação de princípios constitucionais pelo TEPFJ. Logo, em todos os casos analisados o Poder Judiciário apresenta um potencial de ingerência nas regras do jogo, que sofre variações em cada país, alterando também a extensão (local, nacional) do impacto nas regras do jogo político, o que diz respeito também ao modelo de federalismo de cada país. 
Comparado com a Argentina, México e Estados Unidos, a atuação do Judiciário brasileiro é diferenciada. Embora se possa observar no México um tribunal eleitoral especializado e nos Estados Unidos uma corte suprema que alterou notoriamente o resultado de eleições presidenciais do ano 2000, o Poder Judiciário desses países não tem a capacidade de impactar a competição política para além do interesse das partes litigantes. No México, porque as questões eleitorais, ao menos nos casos analisados, não chegaram à Corte Suprema. Nos Estados Unidos, porque o controle de constitucionalidade é difuso e, portanto, a constitucionalidade das leis não pode ser discutida "em tese" ${ }^{\prime 14}$. No caso da Argentina, a Corte Suprema estabeleceu, nos casos estudados, um limite entre questões judicializáveis e não judicializáveis, devendo esses últimos serem definidos pelo Poder Legislativo. Ademais, pouca influência exerceu o modelo de governança eleitoral sobre o padrão de atuação do judiciário em todos os casos analisados.

Dessa forma, conclui-se que o modelo de governança eleitoral brasileiro é resultado não apenas das regras que o institucionalizaram, mas também de uma atuação consolidada no sentido de não apenas resolver o contencioso eleitoral ou impactar as eleições pelos efeitos de uma decisão judicial, mas produzir mudanças no campo do rule making, isto é, inovar nas regras do jogo eleitoral. Tal peculiaridade é também resultado da admissibilidade dos tribunais superiores quanto à análise de qualquer tipo de questão referente ao processo eleitoral, no que é reforçada pela existência de diversos mecanismos de acesso aos tribunais, seja pela via recursal ou originária. Além disso, há forte influência do modelo de federalismo brasileiro no modelo de governança eleitoral, considerando-se a centralização da produção das leis eleitorais no âmbito federal, o que acentua o impacto da decisão das cortes superiores na competição política, fazendo com que a extensão dos efeitos das suas decisões ultrapasse as partes litigantes e se estenda a todos os estados da federação.

(Recebido para publicação em 30 de agosto de 2017)

(Reapresentado em 26 de dezembro de 2018)

(Aprovado para publicação em 22 de março de 2019)

\section{NOTAS}

1 Para Barroso (2009) o ativismo judicial está associado "a uma participação mais ampla e intensa do Judiciário na concretização dos valores e fins constitucionais, com maior interferência no espaço de atuação dos outros dois Poderes." Dentre algumas condutas citadas pelo autor que demonstram uma postura mais ativista do Judiciário está a prá- 
tica da "aplicação direta da Constituição a situações não expressamente contempladas em seu texto e independentemente de manifestação do legislador ordinário". Tal foi o caso do julgamento da "fidelidade partidária", ocasião em que o STF declarou que o mandato pertence ao partido, criando, assim, uma nova hipótese de perda de mandato parlamentar.

2 Marchetti (2008) define os três níveis de operação da governança eleitoral a partir do estudo comparativo de Andreas Schedler e Shaheen Mozaffar (2002), intitulado The Comparative Study of Electoral Governance.

3 Segundo o Portal da Transparência do TSE, no ano de 2013, foram impetrados 20 mandados de segurança e 11 habeas corpus. Disponível em: http:/ /www.tse.jus.br/transparencia/estatistica-processual. Além disso, os processos julgados pelo STF em matéria de direito e processo eleitoral, no ano de 2013, correspondem a apenas $0,46 \%$, num total de 204 processos. Dados disponíveis em: http:/ / www.stf.jus.br/estatisticas.

4 Art. 23, da Lei no 4.737 / 65 (Código Eleitoral): “Compete, ainda, privativamente, ao Tribunal Superior: [...] I - elaborar o seu regimento interno; [...] IX - expedir as instruções que julgar convenientes à execução deste Código; [...] XII - responder, sobre matéria eleitoral, às consultas que lhe forem feitas em tese por autoridade com jurisdição, federal ou órgão nacional de partido político".

5 ADI proposta pelo PPS (Partido Popular Socialista) que discutiu a constitucionalidade do art. $47, \S 2$ o, no que diz respeito à distribuição do horário de propaganda eleitoral gratuita entre todos os partidos com representação na Câmara dos Deputados.

6 Até 10/2/2014, o Instituto Nacional Electoral chamava-se Instituto Federal Electoral (IFE). Tal mudança teve o intuito de coordenar, além das eleições em nível federal, as eleições locais por meio da coordenação dos organismos eleitorais locais.

7 Decretos no $7.163 / 62$ e 6.407/63, respectivamente.

8 Juntas Nacionales Electorales.

9 A "Ley de Lemas" (Lei provincial no 10.524/91) é um mecanismo eleitoral pelo qual cada partido que compete numa eleição se divide em "sublemas" que competem entre si. Trata-se, na verdade, de levar as eleições internas partidárias às eleições gerais.

10 http://www.fec.gov/about.shtml.

11 Caso no 08-205. Disponível em: http:/ / www.supremecourt.gov/Search.aspx?FileName=/ docketfiles/08-205.htm. Acesso em: 22 de maio de 2014.

12 SUP-JRC - 604/2007.

13 SUJ-JRC - 165/2008.

14 Destaca-se que não obstante a presença do instituto de stare decisis, segundo o qual a eficácia dos precedentes da Suprema Corte é erga omnes, isto é, vinculam a todos, no caso Bush vs. Gore a decisão foi per curium, ou seja, limitada às circunstâncias atuais e não poderia ser utilizada como precedente. 


\section{REFERÊNCIAS BIBLIOGRÁFICAS}

BARROSO, Luís Roberto. (2009), "Judicialização, ativismo judicial e legitimidade democrática". Revista de Direito do Estado, 13.

BLANDO, Oscar M. (2002), Derecho y Política: de la Ley de Lemas a la reforma política y constitucional em Santa Fe. Rosario, Argentina: Editorial Juris.

CAMPOS, German Bidart. (1964), "La jurisdiccion judicial y las cuestiones políticas". In: J. S. Fornieles et al. (orgs.), El Derecho. Buenos Aires: Universidad Catolica Argentina, Tomo 9, pp. 915-924.

CAPPELLETTI, Mauro. (1984), O controle de constitucionalidade das leis no direito comparado. Porto Alegre: Sergio Antonio Fabris Editor.

FIORI, José Luis. (1995), "A governabilidade democrática na nova ordem econômica". In: Novos Estudos CEBRAP, n. 43, pp. 157-172.

FLEISCHER, David; BARRETO, Leonardo. (2009), "El impacto de la justicia electoral sobre el sistema político brasileño". América Latina Hoy, n. 51, pp. 117-138.

GILLMAN, Howard. (2001), The votes that counted: how the court decided the 2000 presidential election. Chicago: The University of Chicago Press.

GÓMEZ, Leticia Heras. (2011), “Confianza en las Instituciones Electorales en México: el IFE bajo la mirada ciudadana". Revista Debates, v. 5, n. 1, pp. 9-23.

GRAJALES, Luis Octavio Vado. (2011), “La argumentación judicial electoral en México. El caso Yurécuaro". Justicia Electoral, v. 1, n. 8, Sección de Estados, pp. 313-337. Disponível em: http://www.juridicas.unam.mx/publica/librev/rev/juselec/cont/29/edo/ edo10.pdf. Acesso em: 11 de abril de 2017.

HUNTINGTON, Samuel. (1968), Political order in changing societies. New Haven/London: Yale University Press.

. (1975), "The United States". In: M. Croizier; S. Huntington; J. Watanaki (orgs.), The crisis of democracy: report on the democracies to the trilateral commission. New York: New York University Press. pp. 59-101.

JONES, Clifford A. (2015), "Buckley v. Valeo". In: Encyclopædia Britannica. Disponível em: https:/ / www.britannica.com/event/Buckley-v-Valeo. Acesso em: 23 de dezembro de 2018.

LEMAISTRE, Silvia Gómez Tagle. (2011), Lo que ven otros ojos: las elecciones en México 19882009. México: Tribunal Electoral del Poder Judicial de la Federación.

LIPTAK, Adam. (2010), “Justices, 5-4, Reject Corporate Spending Limit". The New York Times. Nova York, 21 de janeiro de 2010. Disponível em: http:/ / www.nytimes.com/2010/01/22/ us/politics/22scotus.html?pagewanted=all\&_r=0. Acesso em: 19 de maio de 2014.

LÓPEZ-PINTOR, Rafael. (2000), Electoral management bodies as institutions of governance.. New York: United Nations Development Programme.

MARCHETTI, Vitor. (2015), Justiça e competição eleitoral. 2. ed. São Bernardo do Campo: Editora UFABC. 
(2008), "O modelo brasileiro de justiça eleitoral". DADOS - Revista de Ciências Sociais, v. 51, n. 4, 2008, pp. 865-893.

PASTOR, Robert A. (1999), The role of electoral administration in democratic transitions: implications for policy and research. Democratization, v. 6, n. 4, pp. 1-27.

. The US administration of election: decentralized to the point of being dysfunctional. Electoral Management Design: The International IDEA Handbook, novembro de 2006. Disponível em: http://www.idea.int/publications/emd/upload/emd_cs_usa.pdf. Acesso em: 16 de maio de 2019

PEREIRA, Manuela de Souza. (2012), “Governança eleitoral na América Latina: dispositivos constitucionais comparados". Debate. v. 4, n. 3, pp. 41-47.

RIBEIRAL, Tatiana Braz. (2012), Direitos políticos e legislação eleitoral no México e Brasil. Tese de Doutorado, Brasília: Centro de Pesquisa e Pós-Graduação sobre as Américas (CEPPAC) do Instituto de Ciências Sociais/ Universidade de Brasília.

RODRÍGUEZ, Sergio Alonso. (2012), "Reseña de 'sistemas y modelos de control constitucional en México', de Cossío Díaz, José Ramón”. Boletín Mexicano de Derecho Comparado. XLV mai-ago. pp. 771-775. Disponível em: http://www.redalyc.org/articulo. oa?id=42723288011. Acesso em: 11 de abril de 2017.

SADEK, Maria Tereza Aina. (1995), A justiça eleitoral e a consolidação da democracia no Brasil. São Paulo: Fundação Konrad Adenauer-Stiftung.

SÁNCHEZ GIL, Ruben A. (2004), "El Control Difuso de la Constitucionalidad en México: Reflexiones en torno a la Tesis P." /J. 38/2002. Revista Mexicana de Derecho Constitucional [On-line], n. 11, pp. 199-229. Disponível em: http://biblio.juridicas.unam.mx/revista/ CuestionesConstitucionales/numero/11/ard/ard7.htm. Acesso em: 11 de abril de 2017.

SANTOS, Maria Helena de Castro. (1997), “Governabilidade, governança e democracia: criação de capacidade governativa e relações Executivo-Legislativo no Brasil pós-constituinte". DADOS - Revista de Ciências Sociais. v. 40, n. 3. Disponível em: http:/ /www. scielo.br/scielo.php?script=sci_arttext\&pid=S0011-52581997000300003\&lng=en\&nrm =iso. Acesso em: 20 de dezembro de 2018.

TAYLOR, Matthew. (2006), “A justiça eleitoral”. In: L. Avritzer; F. Anastasia (orgs.), Reforma política no Brasil. Belo Horizonte: Editora UFMG. pp. 147-152.

BERIZONCE, R. O. ; TESHEINER, J. M. R. ; THAMAY, R. F. K. “A organização judiciária no Brasil e Argentina”. In: BERIZONCE, Roberto O.; TESHEINER, José M. R.; THAMAY, Rennan Faria Kruger (orgs.). Los Procesos Colectivos: Argentina y Brasil. Buenos Aires: Cathedra Jurídica, 2012. pp. 3-55.

THE ECONOMIST. (2012), "A morning-after constitutional?" The Economist Newspaper Limited. London, 24 de novembro de, pp. 29-30.

WALL, Alan; ELLIS, Andrew; et.al Electoral Management Design: Revised Edition. Suíça: International Institute for Democracy and Electoral Assistance, 2014. Disponível em: http:/ / www.idea.int/sites/default/files/publications/electoral-management-design-2014.pdf. Acesso em: 26 de maio de 2017. 
Ana Paula de Almeida Lopes

ZAMORA, Raúl Montora. (2014), “La influencia de Ronald Dworkin en la Jurisprudencia del Tribunal Electoral del Poder Judicial de la Federación". Revista Mexicana del Derecho Electoral, n. 1, pp. 59-85. Disponível em: http://biblio.juridicas.unam.mx/revista/ pdf/DerechoElectoral/5/ard/ard2.pdf. Acesso em: 11 de abril de 2017.

ZAULI, Eduardo Meira. (2011), "Justiça eleitoral e judicialização das eleições no Brasil". Revista Brasileira de Estudos Políticos. n. 102, pp. 255-289. 


\section{RESUMO}

Governança Eleitoral e Ativismo Judicial: Uma Análise Comparada sobre o Impacto de Decisões Judiciais nas Regras do Processo Eleitoral Brasileiro

O presente trabalho de pesquisa tem por objetivo analisar as especificidades do modelo de governança eleitoral brasileiro sob a perspectiva da judicialização da competição política, a partir de um estudo comparado, a fim de avaliar se as regras institucionais produzem resultados diferentes no que concerne o ativismo judicial em relação ao processo eleitoral. Para identificar as peculiaridades do modelo de governança eleitoral brasileiro, importa avaliar as suas principais características como um órgão judicializado com base em uma análise comparada com outros países que, da mesma forma, apresentam estruturas semelhantes de regimes presidencialistas federativos e de sistema judicial, quais sejam: Argentina, México e Estados Unidos. Sendo assim, o estudo foi alicerçado em quatro critérios de análise: a) modelo de governança eleitoral; b) existência de justiça eleitoral especializada; c) modelo de controle de constitucionalidade; e d) mudança de regras eleitorais e/ou partidárias a partir de decisão judicial. Ao final, concluiu-se que o modelo de governança eleitoral brasileiro é resultado não apenas das regras que o institucionalizaram, mas também de uma atuação consolidada no sentido de não apenas resolver o contencioso eleitoral ou impactar as eleições pelos efeitos de uma decisão judicial, mas produzir mudanças no campo do rule making.

Palavras-chave: governança eleitoral; judicialização da política; competição eleitoral

\section{ABSTRACT \\ Electoral Governance and Judicial Activism: A Comparative Analysis on the Impact of Judicial Decisions on the Rules of the Brazilian Electoral Process}

The present research aims to analyze the specificities of the Brazilian electoral governance model from the perspective of the political competition's judicialization, based on a comparative study, in order to evaluate if the institutional rules produce different results regarding judicial activism in relation to the electoral process. In order to identify the peculiarities of the Brazilian electoral governance model, it is important to evaluate its main characteristics as a judicial body through a comparative analysis with other countries that present similar structures of federative presidential regimes and judicial systems, such as Argentina, Mexico, and the United States. Thus, the study was based on four criteria of analysis: a) model of electoral governance; b) existence of specialized electoral 
justice; c) constitutionality control model; and d) change of electoral and/or partisan rules by judicial decision. Finally, it became evident that the Brazilian electoral governance model is a result not only of the rules that institutionalized it, but also of a consolidated action in order not only to resolve the electoral dispute or to impact the elections through a judicial decision, but also to produce changes in the field of rule-making.

Keywords: electoral governance; judicialization of politics; electoral competition

\section{RÉSUMÉ}

Gouvernance Électorale et Activisme Judiciaire: Analyse Comparative de l'Impact des Décisions de Justice sur les Règles du Processus Électoral Brésilien

La présente recherche vise à analyser les spécificités du modèle de gouvernance électorale brésilien dans la perspective de la judicialisation de la concurrence politique, sur la base d'une étude comparative, afin de déterminer si les règles institutionnelles produisent des résultats différents en ce qui concerne l'activisme judiciaire à l'égard du processus électoral. Pour identifier les particularités du modèle de gouvernance électorale brésilien, il est important d'évaluer ses principales caractéristiques en tant qu'organe judiciaire fondé sur une analyse comparée à d'autres pays qui aient, de la même manière, des structures similaires à régimes présidentiels fédératifs et de systèmes judiciaires. Ces sont: L'Argentine, Le Mexique et L'États-Unis. Ainsi, l'étude reposait sur quatre critères d'analyse: a) modèle de gouvernance électorale; b) existence d'une justice électorale spécialisée; c) modèle de contrôle de constitutionnalité; et $\mathrm{d}$ ) modification des règles électorales et/ou partisanes par rapport à une décision de justice. Finalement, il a été conclu que le modèle de gouvernance électorale brésilien résultait non seulement des règles qui l'institutionnalisaient, mais aussi d'une performance consolidée, non seulement pour résoudre le différend électoral ou pour avoir une incidence sur les élections sous l'effet d'une décision de justice, mais pour produire des changements dans le domaine du rule marketing.

MOTS-CLÉS: gouvernance électorale; judicialisation de la politique; compétition électorale 


\section{RESUMEN \\ Gobernanza Electoral y Activismo Judicial: Un Análisis Comparado sobre el Impacto de Decisiones Judiciales en las Reglas del Proceso Electoral Brasilero}

El presente trabajo de investigación tiene por objetivo analizar las especificidades del modelo de gobernanza electoral en Brasil desde la perspectiva de la judicialización de la competencia política, a partir de un estudio comparado, con el fin de evaluar si las reglas institucionales producen resultados diferentes en lo que concierne al activismo judicial en relación al proceso electoral. Para identificar las peculiaridades del modelo brasilero de gobernanza electoral, importa evaluar sus principales características como un órgano judicializado con base en un análisis comparado con otros países que, de igual forma, presentan estructuras semejantes de regímenes presidencialistas federativos y de sistema judicial, tales como: Argentina, México y Estados Unidos. De esta forma, el estudio fue basado en cuatro criterios de análisis: a) modelo de gobernanza electoral; b) existencia de justicia electoral especializada; c) modelo de control de constitucionalidad; y d) cambio de reglas electorales y/o partidarias a partir de decisión judicial. Finalmente, se concluye que el modelo brasilero de gobernanza electoral es resultado no solamente de las reglas que lo institucionalizaron, sino también de una actuación consolidada en el sentido de no resolver únicamente el contencioso electoral o impactar las elecciones por los efectos de una decisión judicial, sino producir cambios en el campo del rule making.

Palabras clave: gobernanza electoral; judicialización de la política; competencia electoral 